\title{
Pathological Responses to Terrorism
}

\author{
Rachel Yehuda*,', Richard Bryant', Charles Marmar' and Joseph Zohar' \\ 'Psychiatry OOMH, Bronx Veterans Affairs Medical Center, Bronx, NY, USA
}

\begin{abstract}
Many important gains have been made in understanding PTSD and other responses to trauma as a result of neuroscience-based observations. Yet there are many gaps in our knowledge that currently impede our ability to predict those who will develop pathologic responses. Such knowledge is essential for developing appropriate strategies for mounting a mental health response in the aftermath of terrorism and for facilitating the recovery of individuals and society. This paper reviews clinical and biological studies that have led to an identification of pathologic responses following psychological trauma, including terrorism, and highlights areas of future-research. It is important to not only determine risk factors for the development of short- and long-term mental health responses to terrorism, but also apply these risk factors to the prediction of such responses on an individual level. It is also critical to consider the full spectrum of responses to terrorism, as well as the interplay between biological and psychological variables that contribute to these responses. Finally, it is essential to remove the barriers to collecting data in the aftermath of trauma by creating a culture of education in which the academic community can communicate to the public what is and is not known so that survivors of trauma and terrorism will understand the value of their participation in research to the generation of useful knowledge, and by maintaining the acquisition of knowledge as a priority for the government and those involved in the immediate delivery of services in the aftermath of large-scale disaster or trauma. Neuropsychopharmacology (2005) 30, I793- 1805. doi:I0.1038/sj.npp. I 3008 I6; published online I 3 July 2005
\end{abstract}

Keywords: terrorism; posttraumatic stress disorder; risk factors; biological studies; prospective studies

\section{INTRODUCTION}

Some individuals are vulnerable to the development of psychopathology following exposure to events that elicit terror and helplessness, but the majority of persons show only transient symptoms that, for the most part, resolve within weeks or months. One of the major gaps in our knowledge is that it is difficult to predict long-term responses to trauma on the basis of the nature and time course of the acute response to any traumatic event-particularly for any given individual. This paper summarizes what is and is not known about predicting psychopathologic responses following exposure to psychological trauma for the purpose of highlighting fruitful areas for future research about the effects of terrorism.

\section{ARE PSYCHOLOGICAL OUTCOMES RELATED TO TERRORISM COMPARABLE TO THOSE OBSERVED IN THE CASE OF OTHER LIFE-THREATENING EVENTS?}

Defining pathological responses to terrorism requires determining whether and to what extent conclusions about

*Correspondence: Dr R Yehuda, Psychiatry OOMH, Bronx Veterans Affairs Medical Center, I 30 West Kingsbridge Road, Bronx, NY 10468 , USA, Tel: + I 7185849000 ext. 6964, Fax: + I 718741 4775,

E-mail: Rachel.Yehuda@med.va.gov

Received 2 March 2004; revised 15 September 2004; accepted 21 September 2004

Online publication: 2 June 2005 at http://www.acnp.org/citations/ Npp060205040098/default.pdf the effects of trauma exposure arising from other situations are applicable to issues relating to terrorism and mass violence. Terrorism is a prototypic traumatic event (ie that meets the objective and subjective criteria as defined according to the DSM-IV), for those who directly experience a threat to their life or physical integrity or who experience loss, most notably, sudden loss of a loved one. However, terrorism is not only about life threat to single individuals, or even a small group of persons, but is designed to instill fear in society at large. Thus, in addition to those who experience the effects of terrorism first-hand, there are collateral effects. Persons who are not in proximity to the target of where the terrorist event occurred, or persons who were not directly affected by the loss of someone important to them, can also be affected in terms of mental health outcomes, particularly since such events often receive repeated coverage on television and other media outlets. One of the gaps in our knowledge concerns whether the mental health consequences in persons indirectly exposed to terrorism are qualitatively or quantitatively different from those who have been directly exposed. The additive effect of anticipatory anxiety is also not known, yet the real threat of imminent attack may be related to how quickly those exposed to terrorism can recover from its effects.

A key variable in considering pathological outcomes is the passage of time. This is particularly true in considering outcomes such as PTSD, a diagnosis that requires symptoms and functional disturbances to have persisted for at least one month following trauma exposure. However, terrorist acts usually initiate anxiety about future attacks. If 
a terrorist event represents the beginning or continuation of a situation or threat - as it often does - the timetable for recovery may be shifted. In considering whether the effects of terrorism are pathological, it may, therefore, be appropriate to extend the passage of time in which initial symptoms are considered normal responses. Specifically, it may be more realistic to conceptualize normal responses to terrorism to be present for a longer period of time than 30 days after the initial trauma. In the context of ongoing terrorist threat, identifying persistent disorder may be more accurately defined only after the immediate threat of terrorism is substantially reduced in reality. This caveat does not suggest that people do not have mental health needs that should be met within this timeframe. Instead, it acknowledges that disorder needs to be defined in the context of actual ongoing threat, and that a normative response may involve strong stress reactions if actual threat is still present.

\section{WHAT IS A PATHOLOGIC RESPONSE?}

In trying to delineate the mental health consequences of terrorism, researchers have generally conducted surveys or interviews in which they inquire about expectable emotional reactions. These include difficulties in sleeping and concentrating, irritability, nightmares, distressing thoughts about the event, or distress at reminders of the event (Schuster et al, 2001), that is, symptoms suggestive of PTSD. In the immediate aftermath of terrorism, most people will exhibit these symptoms. The question becomes whether having even an abundance of such symptoms at a time when most persons seem to (understandably) have them constitutes, let alone predicts, pathology. Although hypervigilence to future attacks or persistent worry about exposure to anthrax may have been widely present following the attacks of $9 / 11$, is it best to consider these symptoms as indicative of a pathological or normative response in a terrorist environment? Most mental health models regard acute stress reactions as mental disorder, but it may be erroneous to attribute symptoms of anxiety to a mental disorder when the context suggests that such reactions are warranted. The question of how to think about such symptoms is important from a public health perspective since it raises the even greater issue of whether or not the presence of early symptoms requires intervention. The proposition is in accord with recent commentators, who have noted that a definition of disorder should recognize the extent to which a condition is dysfunctional in the context of the situation in which the individual is functioning (Wakefield, 1996).

The longitudinal perspective also provides insight into the pathological nature of acute responses to terrorism. It is now clear that most people recover from early posttraumatic symptoms. This phenomenon can be illustrated by results of surveys conducted by the New York Academy of Medicine following the attacks of 11 September in New York City. Five to eight weeks after the attacks, a prevalence rate of $7.5 \%$ of randomly sampled subjects living south of 110th Street reportedly had developed PTSD (Galea et al, 2002), with those having the most severe exposure or personal loss at higher risk than others. When another randomly sampled group was studied 6 months after the attacks, only $0.6 \%$ of those living south of 110 th street met full diagnostic criteria for PTSD, and an additional $4.7 \%$ met criteria for subsyndromal PTSD (Galea et al, 2003). Certainly, one can conclude from these findings that there was substantial recovery of the Manhattan community as a whole from the initial effects of the 11 September attacks. However, an important question raised by these findings is whether the initial estimates of PTSD based on early symptoms constituted a real clinical syndrome requiring treatment, or rather, was simply a reflection of temporary distress. Obviously, in some persons who did not recover, or had persistent features of PTSD even if they partially recovered, these symptoms may have been the earliest manifestations of psychopathology, raising a second important question of the extent to which early symptoms post-terrorism are predictive of later ones.

\section{CORE PREDICTORS AND HYPOTHESIZED MECHANISMS OF CHRONIC DYSFUNCTION IN THE ACUTE PHASE: CAN PATHOLOGIC RESPONSES BE IDENTIFIED EARLY ON?}

Persons with minimal symptoms in the immediate aftermath of a traumatic event are not at risk for the development of subsequent PTSD or other forms of psychopathology (Shalev, 1992). However, researchers have generally failed to demonstrate that the severity of intrusive, avoidance, and hyperarousal symptoms immediately following a traumatic event are associated with the later development of PTSD (McFarlane, 1989; Shalev, 1992). Rather, greater symptom severity from 1 to 2 weeks posttrauma and onwards is positively associated with subsequent symptom severity (Harvey and Bryant, 1998; Murray et al, 2002; Shalev et al, 1997). Thus, those who show high magnitude PTSD symptoms in the immediate days posttrauma represent two distinct subgroups comprised of those for whom symptoms will abate within a few days, and those for whom symptoms will continue to be present. These findings support the idea that the 'pathologic process' involved in PTSD, and possibly other post-traumatic mental health reactions, are a reflection of a failure of recovery of early symptoms. Yet because the intensity of intrusive, avoidance, and hyperarousal symptoms in the immediate aftermath of a trauma are not direct predictors of a failure to recover, the findings imply the necessity of other predictors of longer-term pathology.

One predictor of long-term psychopathology may be peritraumatic dissociation. Numerous studies have found an association between peritraumatic dissociation and the subsequent development of PTSD (eg Marmar et al, 1994, 1999; Ehlers et al, 1998; Koopman et al, 1994; Murray et al, 2002; Shalev et al, 1998a). Peritraumatic dissociation refers to a dissociative experience that occurs at the actual time of the traumatic event. One recent meta-analysis reported that peritraumatic dissociation was the single best predictor of $(r=0.35)$ PTSD among trauma-exposed individuals (Ozer et al, 2003), but this view has not been unanimously supported in prospective studies (eg Dancu et al, 1996; Marshall and Schell, 2002). In a recent review, McNally and co-workers asserted that findings of the predictive power of 
peritraumatic dissociation are difficult to interpret because many studies do not adequately distinguish between true peritraumatic dissociation and subsequent depersonalization and derealization in the first weeks after exposure, which are required for a diagnosis of ASD, and which does not appear to be predictive of PTSD over and above the acute reexperiencing, and presence of avoidance and arousal symptoms. More importantly, studies of peritraumatic dissociation usually do not covary for cognitive ability, which in itself is a risk factor for PTSD that is linked with dissociation (McNally et al, 2003). Thus, it may be that peritraumatic dissociation predicts PTSD because it is highly linked with other risk factors for this disorder, in particular peritraumatic panic (Brunet et al, 2001; Marmar et al, 2003).

Another potentially important predictor of pathological outcomes following trauma exposure is the presence of a panic attack during and/or immediately after trauma exposure. There is evidence that panic attacks occur in $53-90 \%$ of trauma survivors who experience a severely traumatic event (Bryant and Panasetis, 2001). More than half of persons who meet criteria for ASD report peritraumatic as well as subsequent panic attacks. Galea et al found peritraumatic panic to be the best predictor of PTSD in the post 9/11 survey of 1008 residents living south of 110 St in Manhattan. This observation is consistent with recent observations from a study of 747 police officers, in which panic reactions and related emotional distress during exposure were highly predictive of pre 9/11 PTSD symptoms (Brunet $e t a l, 2001$ ) and in a prospective study of 311 NYPD officers also predictive of post 9/11 symptoms (Marmar et al, 2003).

McNally et al (2003) have suggested that both peritraumatic dissociation and peritraumatic panic can result in a catastrophic interpretation of the event and or the erroneous conclusion that the symptoms are harbingers of more serious problems. Indeed, some investigators have demonstrated the power of negatively appraising any aspect of the event in the peritraumatic period to predict long-term pathology. For example, having a negative perception of other people's responses (eg, I feel that other people are ashamed of me now) predicts PTSD beyond what can be predicted from initial symptom levels (Dunmore et al, 2001). People with ASD are prone to catastrophize about somatic cues (Smith and Bryant, 2000), and also respond to a hyperventilation challenge test by engaging in more dysfunctional thoughts about somatic responses. Similarly, catastrophic attributions of responsibility for a trauma in the acute post-trauma phase predicts PTSD (Andrews et al, 2000; Delahanty et al, 1997). The presence of these attributions provide a way of drawing a distinction between being terrorized and being terrified. A person exposed to a traumatic event is not 'traumatized' unless they are deeply distraught at the time of the event and then make catastrophic interpretations.

Basic science research on both memory consolidation and fear conditioning has demonstrated that heightened adrenergic activation can promote the consolidation and retrieval of fear-provoking memories (Bohus and Lissak, 1968). Developing this preclinical work, conditioning models of trauma response posit that PTSD is the result of strong associative learning whereby individuals initially react to a traumatic event (unconditioned stimulus) with arousal and fear (unconditioned response). Individuals with PTSD then continue to show arousal (conditioned response) when confronted with trauma-related cues (conditioned stimuli). It has been hypothesized that extreme sympathetic arousal at the time of a traumatic event may result in the release of stress-related neurochemicals (including norepinephrine and epinephrine) into the cortex, mediating an overconsolidation of trauma memories (Pitman et al, 2000). The majority of trauma survivors will engage in extinction learning in the weeks after trauma exposure, in which they associate the conditioned stimuli with safe consequences, and thereby inhibit the fear response. In contrast, the minority of people who develop PTSD suffer from impaired extinction learning resulting in a condition in which they become more sensitized, rather than desensitized to their memories of the trauma. Both dissociation (Simeon et al, 2003) and panic reactions (Charney et al, 1993; Southwick et al, 1993) have been associated with increased catecholamines states. It is plausible that persons displaying peritraumatic panic, dissociation, or intense distress during and immediately after the traumatic event have higher levels of catecholamines than those who do not respond in this manner. An enhanced elevation of catecholamines in the immediate aftermath of a traumatic event may increase the probability of intrusive recollections in the first few days and weeks post-trauma. Relevant to this proposition's recent evidence that low GABA plasma levels immediately after trauma are predictive of subsequent PTSD (Vaiva et al, 2004). In light of evidence that GABA modulates the HPA axis and that GABA agonists reduce fear reactions (Zangrossi et al, 1999), this finding suggests that lower GABA levels shortly after trauma may suppress glutamatergic functioning. This observation is consistent with evidence that intoxication at the time of trauma can reduce PTSD development (Maes et al, 2001).

One of the major gaps in our knowledge concerns the interplay of biologic responses at the time of a traumatic event and cognitive factors. Indeed, it is easy to see how an increased catecholaminergic response to trauma could be the proximal cause of intense panic. Furthermore, it seems plausible that persons who find themselves in a more intense biologic state of fear might be likely to appraise a situation as more immediately dangerous. On the other hand, it may be that pre-existing cognitive factors mediate the catcholaminergic response to the trauma that leads to the panic. These pre-existing cognitive factors, in turn, may or may not be the cause, result, or correlate of a pre-existing biological alteration that sets the stage for an extreme response.

In summary, those who are exposed to terrorism or other catastrophic events and do not panic, do not develop high levels of other dysphoric emotions, and have low levels of PTSD-like symptoms in the first days and weeks after exposure will likely not develop PTSD. Among those who are having high levels of symptoms in the first days or weeks, some will recover and some will not.

Clarifying the causes of high levels of immediate and long-term symptoms will no doubt lead to ideas about potential preventative treatments. For example, to the extent that panic reactions are associated with increased catecholamine responses at the time of trauma, aggressive 
intervention with adrenergic blocking agents such as propranolol (Pitman et al, 2002; Vaiva et al, 2004) or cognitive behavioral stress management techniques emphasizing relaxation rather than any form of 'retelling' (ie reexposure, as in 'debriefing') may be the most appropriate immediate interventions for persons who panic in the hours immediately following a traumatic experience. For persons who are not in a position to receive intervention within several hours or days post-trauma, it will be necessary to determine the impact of post-traumatic risk factors such as lack of social support on the longitudinal course of pathologic responses to trauma.

What seems particularly important, however, is that there is not a linear relationship between acute stress reactions and longer-term adjustment. A small proportion of people can apparently develop PTSD, or other disorders, after a delayed period of time following the initial traumatic event. DSM-IV identified delayed-onset PTSD as a way of understanding the appearance of disorder at least 6 months after the precipitating event. Large-scale studies of civilian trauma have reported delayed onset PTSD in a small minority of cases (around 5\%; Bryant and Harvey, 2002; Buckley et al, 1996; Ehlers et al, 1998; Mayou et al, 1993). There is evidence that people who develop delayed onset PTSD experience more persistent stressors after the initial trauma, which may contribute to PTSD development (Ehlers et al, 1998; Solomon et al, 1989; Green et al, 1990). It is possible that ongoing stressors in the aftermath of an initial terrorist attack (eg biological agents, subsequent threat of attacks) may contribute to later development of PTSD. Alternately, fear-conditioning models posit that initial conditioning may persist in a latent form until sufficient cues, or increased stressors, may elicit a conditioned response in the form of PTSD (Charney et al, 1993). Fear-conditioning models suggest that there should be some form of fear reaction in the acute phase, and that this should be exacerbated under certain circumstances that reinstate the initial fear-related cues. This idea is supported by evidence that most people who develop delayed onset PTSD do display elevated stress reactions and higher resting heart rates in the acute phase after trauma exposure (Bryant and Harvey, 2002).

\section{RISK PROFILING}

Although being able to potentially predict long-term pathology from the acute response, such as peritraumatic panic, is of paramount importance, understanding the development of pathologic responses will ultimately also necessitate understanding the risk factors for those early responses. The finding that only a proportion of those exposed to trauma develop short- and long-term symptoms justifies an exploration of both the factors that increase the risk for, as well as the factors that might serve to protect individuals from, developing such symptoms following trauma exposure. Although technically, putative risk factors for PTSD can describe both the characteristics of the event or the response to the event, and the characteristics of persons who experience those events, we limit our discussion here to pre-existing risk factors. A wide variety of risk factors, ranging from situational or environmental factors, to familial or even genetic risk factors for PTSD have now been identified (eg Yehuda, 1999a, b).

It appears on the basis of retrospective studies that those at greatest risk for developing PTSD following a traumatic event are persons with a family history of psychopathology (Breslau et al, 1991), prior exposure to trauma (Nishith et al, 2000; Breslau et al, 1999), cognitive factors, such as lower IQ (Silva et al, 2000), female gender (Breslau et al, 1999), and certain pre-existing personality traits, such as proneness to experiencing negative emotions and having poor social supports (Brewin et al, 2000). To a large extent, prospective studies have supported these findings, in that persons showing less recovery tended to have more of these risk factors than those who did not. However, when such risk factors have been used in discriminant function analyses to predict subsequent PTSD in prospective studies, no single variable emerged as a significant predictor. This may reflect the fact that retrospective studies use a more narrow range of subjects that are classified based on the dichotomy of the presence or absence of PTSD, whereas prospective studies may include a broader range of people making such predictions more difficult.

Recent work has begun to identify risk factors by assessing populations that are likely to be exposed to trauma before and after exposure. A recent prospective study of New York police officers found that elevated symptoms of PTSD assessed several years prior to 9/11 predicted greater 9/11-related PTSD symptoms several years after the WTC attacks (Marmar, 2003, unpublished observations). A recent study of startle responses found that skin conductance and eyeblink EMG startle responses before trauma exposure in a cohort of firefighter trainees predicted acute stress reactions after subsequent trauma exposure (Guthrie and Bryant, 2005). Further, slower extinction learning after aversive conditioning before trauma exposure strongly predicted chronic post-traumatic stress after trauma exposure (Guthrie and Bryant, unpublished observations). Collectively, these findings point to the importance of psychophysiological reactivity prior to trauma exposure as a risk factor for subsequent fear conditioning and development of post-traumatic stress.

Family and genetic studies are pointing towards the role of genetic contributions to post-traumatic stress reactions. Adult children of Holocaust survivors with PTSD show a greater prevalence of PTSD to their own traumatic events compared to adult children of Holocaust survivors without PTSD (Yehuda et al, 1998). It is difficult to know to what extent increased vulnerability to PTSD in family members of trauma survivors with PTSD can be attributed to being raised by a parent with this disorder (Yehuda et al, 2001), to exposure of the fetus to the mother's stress hormones during pregnancy, or to genetic factors. Recent twin studies are indicating the role of genetic contribution, given the increased prevalence of PTSD in monozygotic compared with dizygotic twins (Stein et al, 2002; True et al, 1993). Further, a recent study compared startle responses in pairs of Vietnam combat veterans and their noncombat-exposed monozygotic twins (Orr et al, 2003). This study found evidence of more slowly habituating skin conductance startle responses in veterans with PTSD and their noncombat-exposed co-twins, compared to veterans without PTSD and their noncombat exposed co-twins. This finding 
suggests that more slowly habituating skin conductance responses to startle stimuli may represent a pretrauma vulnerability factor for PTSD (Orr et al, 2003).

The issue that is raised by these risk factors is whether they need to be part of an initial assessment in the immediate aftermath of a trauma, and this is currently an open question. Studies have clearly demonstrated that persons with high PTSD symptoms in the first week who have additional risk factors-childhood trauma, low educational attainment, personal or family history of anxiety or mood disorders, history of heavy alcohol use in the months prior to the incident, poor social supports in the post-traumatic period, and greater levels of exposure during the incident - are less likely to recover than those who do not. However, if panic and related emotional distress at the time of the traumatic event, or if a high level of PTSD symptoms that substantially interfere with occupational and relationship functioning within the weeks following an event, are sufficiently predictive of longer-term symptoms, it may not be necessary to assess pretraumatic risk factors for the purpose of triage and intervention. Rather, those risk factors might prove important in understanding and possibly differentiating among different types of acute reactions, and for the purpose of providing prophylaxis.

\section{THE ROLE OF BIOLOGIC STUDIES IN HELPING TO IDENTIFY PATHOLOGIC RESPONSES}

The biologic component of PTSD has become increasingly relevant to the issue of pathologic responses. Initially, one of the major intellectual cornerstones for early conceptions of a biologic component to PTSD were studies of the biology of stress, which essentially justified a normal continuum of responses to adversity based on a dose-response model (ie the greater severity of the traumatic event, the greater the biologic response). Although a comprehensive review of the neurobiology of PTSD is beyond the scope of this paper, there are important implications of neurobiological studies of PTSD to the issue of pathological responses to trauma. First and foremost is that there does appear to be a distinct set of biological alterations associated with PTSD, at least some of which reflect changes in stress-responsive systems that are qualitatively different from those what would be predicted on the basis of the stress literature. Furthermore, the alterations in individuals with PTSD have been found to be distinct from those of similarly exposed individuals without PTSD, and also different from those found in other psychiatric disorders, such as mood and other anxiety disorders. Together, these findings suggest that the biology of PTSD is not simply a reflection of a normative stress response, but rather, a pathologic one (Yehuda and McFarlane, 1995).

In tandem with observations of the phenomenology and psychology of PTSD, neurobiological examinations of trauma survivors have also supported the possibility that the development of PTSD is facilitated by a failure to contain the normal stress response at the time of the trauma, resulting in a cascade of biological alterations that lead to intrusive, avoidance, and hyperarousal symptoms. In contrast to the normal fear response, which is characterized by a series of biological reactions that help the body cope with, and gradually recover from, stress (eg high cortisol levels), some recent prospective biologic studies have demonstrated that individuals who develop PTSD or PTSD symptoms appear to have attenuated cortisol increases in the acute aftermath of a trauma than those who do not develop this disorder (Resnick et al, 1995; Delahanty et al, 2000). Moreover, persons who develop PTSD show higher heart rates in the emergency room and at one week post-trauma compared to those who ultimately recover (Bryant et al, 2000; Shalev et al, 1998b), suggesting a greater degree of sympathetic nervous system activation. These findings imply that the actual biologic response to acute trauma may be altered in persons who develop PTSD, some of which are typical of and others atypical of the 'normal' stress response.

Relevant to the issue of the transition from transient stress reaction to pathological stress response are sensitization models of PTSD. Post et al (1995) have proposed that exposure to an intense stimulus induces a range of immediate arousal symptoms, and that these reactions gradually decrease over time and are replaced with conditioned responses in which environmental cues trigger reexperiencing and arousal symptoms. With chronic repeated stimulation by trauma cues, reexperiencing symptoms begin to occur spontaneously, rather than require triggering, in a kindling-like process. This stress sensitization model therefore predicts a 'temporal evolution' to the development of PTSD symptoms after trauma (Post et al, 1995, p. 218). Consistent with this model, one study assessed eyeblink, heart rate, and skin conductance responses to startling tones in civilian trauma survivors at 1 week, 1 month, and 4 months following trauma exposure (Shalev et al, 2000). Elevated heart rate and more slowly habituating skin conductance and EMG responses to startle stimuli were observed at 1 and 4 months following trauma but not at 1 week after trauma in those who subsequently developed PTSD. These results suggest a progressive neuronal sensitization associated with heightened physiological reactivity underlying PTSD development. At this point, we have insufficient data to identify the temporal milestones following trauma in which sensitization develops, but this is an important goal for future research that attempts to discriminate between adaptive and maladaptive trauma responses.

The precise origin and onset of any of the biologic alterations associated with PTSD have not been elucidated. Furthermore, as with most psychiatric disorders, no one biologic alteration has been found to be pathognomic, or associated reliably enough with PTSD to serve as a diagnostic marker in either the acute or chronic phase of the disorder. In fact, consistent with biologic heterogeneity in persons with PTSD, recent findings suggest that at least some of the biologic alterations observed (eg low cortisol levels; decreased hippocampal volumes) may represent a pre-existing risk factor for the disorder rather than either a consequence of trauma exposure or a reflection of the pathophysiologic expression of the disorder (Yehuda et al, 2000; Gilbertson et al, 2002).

It is not currently understood how pre-existing biologic risk factors might influence a person's response to an acute trauma, but it is important to develop models, and then testable hypotheses for how this might occur. With respect 
to the neuroendocrine alterations, if, for example, low cortisol levels were risk factors for PTSD in some people it would be possible, since cortisol inhibits its own release through negative feedback at the level of the pituitary and the hypothalamus, that lower levels of cortisol at the time of a traumatic event would disrupt the process of stress recovery by failing to inhibit the activation of the pituitary resulting in increased hypothalamic CRF stimulation in synergy with other neuropeptides, such as arginine vasopressin, resulting in a higher magnitude ACTH response, which might further stimulate the sympathetic nervous system (Holsboer, 2001). Moreover, since glucocorticoid release inhibits norepinephrine secretion from the sympathetic nerve terminals, lower cortisol levels may have the consequence of prolonging norepinephrine availability to synapses both in the periphery and in the brain (Pacak et al, 1995). Ultimately, low cortisol levels might result in an upregulation or increased sensitivity of glucocorticoid receptors in response to the detection of a greater internal demand by the pituitary, and this would further strengthen negative feedback inhibition. Alternatively, an enhanced negative feedback inhibition may be present at the time of the trauma, and may contribute to the premature suppression of ACTH and cortisol, leading to undermodulated catecholamine responses (Yehuda, 2002).

There may be consequences of increased catecholamine levels in the acute aftermath of the trauma for promoting the consolidation of the traumatic memory. Indeed, adrenergic activation in the face of low cortisol has been shown to facilitate learning in animals (Cahill et al, 1994; de Quervain et al, 2000). If this were also occurring in trauma survivors, the memory of the event would not only be strongly encoded, but associated with extreme subjective distress. The distress, in turn, could facilitate the development of altered perceptions and thoughts in the aftermath of the event, particularly those associated with one's own perception of danger or ability to cope with threat. These altered beliefs could serve to further delay recovery by leading to a failure to quell fearful responses, which would further serve to strengthen, rather than reduce, both maladaptive cognitions in response to trauma and fear responses thus perpetuating the intrusive, avoidance, and hyperarousal symptoms as described above. In this context, there is evidence that trauma survivors with ASD in the initial month after trauma display greater theta EEG activity than non-ASD trauma survivors. Theta EEG activity has been associated with overconsolidation of memories (Klimesch et al, 1996). This cascade could also produce a series of secondary biological changes. Indeed, the exaggerated physiologic response to startle in PTSD is only observed 1 month post-trauma, but not earlier, reflecting a developmental progression of at least some aspects of the biology of PTSD (Yehuda, 2002).

Thus, the biology of PTSD appears to be one in which there may be a set of pretraumatic biological risk factors that serve to impede the individual's ability to contain the stress response. It is conceivable that any one of a number of biologic risk factors would have the effect of facilitating a biological sensitization to subsequent traumatic events by allowing for a heightened level of physiologic arousal and consequent distress at the time of the traumatic event. It is also possible that different biologic risk factors result in substantively different biologic profiles in PTSD patients, associated with specific symptoms (or symptoms associated with 'comorbid' diagnoses). In a strong demonstration of this possibility, Southwick et al (1997) demonstrated that in certain PTSD patients, panic attacks and flashbacks were elicited by manipulation of the noradrenergic system with yohimbine, whereas in others, they were elicted by manipulation of serotonergic neurotransmission with mCPP. Certainly, PTSD has been associated with numerous other biologic alterations including immune (Wong, 2002), catecholaminergic (Southwick et al, 1993), psychophysiologic (Orr, 1997) alterations, and changes in sleep architecture (Neylan et al, 2003). Importantly, both structural and functional neuroimaging studies of PTSD have demonstrated changes in brain volume and/or activation in regions such as the hippocampus and the amygdala (Rausch et al, 1997). One model proposes that PTSD is influenced by excessive amygdala activation resulting from diminished inhibitory regulation of the rostral anterior cingulate (Bush et al, 2000; Shin et al, 2001). These biological factors could be studied prospectively and in high-risk samples to determine the role that they play in the genesis of PTSD. It is now critical to consider more carefully the relationships between biologic alterations in PTSD and symptoms, and particularly between biologic alterations that may have been present prior to or during trauma exposure, and the subsequent development of pathologic responses.

\section{WHEN CAN A RESPONSE BE CONSIDERED PATHOLOGICAL?}

One of the formal attempts to recognize initial pathological responses to trauma was the introduction of the ASD diagnosis in DSM-IV (American Psychiatric Association, 1994). This diagnosis was intended to fill what was considered to be a diagnostic gap because the PTSD diagnosis only encompasses persistent post-trauma symptoms that are experienced after the first month following the trauma exposure. A second purpose of the diagnosis was to identify acutely traumatized people who were likely to develop chronic PTSD (Koopman et al, 1995). Thus, the ASD diagnosis attempted to differentiate between the majority of trauma survivors who display a transient stress reaction and those who display the initial phase of a chronic disorder.

There are now 12 prospective studies of adults that have addressed the extent to which ASD within the initial month after trauma exposure predicts subsequent PTSD (Brewin et al, 1999; Bryant and Harvey, 1998; Difede et al, 2002; Harvey and Bryant, 1998, 1999, 2000; Holeva et al, 2001; Murray et al, 2002; Schnyder et al, 2001; Staab et al, 1996). Most of these studies demonstrate that approximately threequarters of trauma survivors who display ASD subsequently develop PTSD. However, only a minority of people who eventually developed PTSD initially met criteria for ASD. It appears that a major reason the ASD diagnosis does not adequately identify the majority of people who develop PTSD is the requirement that three dissociative symptoms be displayed (Bryant, 2003). Evidence suggests that there are multiple pathways to developing PTSD that may or may not involve dissociation (Harvey and Bryant, 2002). 


\section{SUMMARY OF WHAT IS KNOWN}

Assuming the responses of New Yorkers to $9 / 11$ can be generalized, most people who are distressed in the first weeks will recover from the effects of terrorism. Those at risk for long-term symptoms appear to have a more intense reaction at the time of the trauma (eg peritraumatic dissociation, panic, or related emotional distress), associated with a more negative appraisal of danger. It is not clear whether and to what extent pretraumatic risk factors (eg pre-existing psychopathology, prior adversity, family history of psychopathology including PTSD and panic disorder, low IQ and other cognitive risk factors, preexisting personality traits such as avoidance and/or neuroticism) influence the intensity of the peritraumatic response to trauma, but presumably, these risk factors are more relevant in situations where exposure is less severe. Post-traumatic risk factors, such as lack of social support, also seem to be important predictors of psychopathology, but the extent to which these reflect pre or even peritraumatic risk factors is currently unknown.

Biological characteristics of those at risk for developing PTSD appear to potentially involve pre-existing alterations that might compromise adaptive cognitive processing at the time of the event (eg lower IQ, prior trauma) and/or preexisting alterations that might impede containment of the biologic response to fear (eg lower cortisol or additional neuropeptides that might fail to contain sympathetic nervous system arousal). It is not known whether these biologic risk factors are related to biologic factors, such as increased catecholamines, which may be present in tandem with and influence levels of peritraumatic panic or distress.

\section{Strength of the Evidence}

Studies of persons who do not recover from the psychological effects of trauma are in general agreement with the predictive power of peritraumatic dissociation and peritraumatic panic attacks. What remains somewhat disputed is whether peritraumatic dissociation and panic are proxies for other PTSD risk factors such as negative appraisal or cognitive performance, or alternatively whether the experiences of dissociation and panic during exposure characterize the state of being traumatized, and drive subsequent negative appraisals regarding self-efficacy and safety. As these studies generally call for retrospective analysis (usually within days or weeks of the traumatic event, however), it is possible that some bias is introduced. That is, very few studies report on actually observing peritraumatic dissociation or panic occurring in real time since investigators are not generally at the seen of a traumatic event to witness this first hand. Also, the majority of studies documenting peritraumatic dissociation and panic attacks have not been direct examinations of survivors of terrorism.

With respect to biologic alterations in chronic PTSD, the conclusion that PTSD is associated with neuroendocrine, neurotransmitter-related, and neuroanatomic alterations is warranted, as there has been some replication across different groups of trauma survivors at different phases of the chronic PTSD condition. However, no single biologic measure or even pattern of biologic measures has been demonstrated to be sufficiently sensitive and specific to constitute a reliable and valid diagnostic test of PTSD. Furthermore, it is not clear whether any of the biologic alterations observed constitute pre-existing risk factors for the disorder rather than consequences of trauma exposure or failure to recover from the biologic responses to stress. Twin studies can partially address this issue. Studies examining biologic alterations prospectively beginning soon after trauma exposure have produced reproducible, but not universal, results and primarily only in studies evaluating more homogenous groups of trauma survivors (eg following the trauma of rape or motor vehicle accidents). Indeed, biologic alterations in the peri- and post-traumatic periods are likely to be highly influenced by many individual differences in both stress exposure and personal characteristics. Difficulties in recruiting subjects for detailed biologic studies in both the immediate aftermath of trauma and more chronic PTSD studies can result in a selection bias with respect to subjects both willing and eligible to participate. Whether biologic alterations observed in other groups of subjects with PTSD would be similar to those observed in victims of terrorism with mental health symptoms is not currently known and represents a critical frontier. Certainly, to the extent that biologic alterations represent either specific risk factors for trauma exposure or PTSD, it is imperative to determine whether pathologic responses to terrorism are similar, from a biologic perspective, to those observed in other groups with PTSD related to combat, rape, accidents, or other forms of interpersonal violence. It is also important to determine whether there are biologic alterations associated with the more nonspecific effects of terrorism, such as anticipatory anxiety, that could affect the pathophysiology and biology of other chronic psychiatric and medical conditions.

\section{IMMEDIATE GAPS IN KNOWLEDGE}

Although many important strides have been made in understanding PTSD and other responses to trauma, there remain many gaps in our knowledge. The following is a partial list of the gaps that currently impede our ability to predict those who will develop pathologic responses or to develop appropriate strategies for facilitating their recovery.

\section{Paucity of Prospective Information About Acute Responses to Terrorism, as well as Pre- and Post-Traumatic Risk Factors for Psychopathology}

There is an important need to obtain prospective data on the effects of terrorism within the initial peri- and posttraumatic period, and to subsequently follow the same people over several years to accurately identify the course of post-traumatic responses in the context of terrorism. Such studies need to include biologic markers of mental and physical illnesses. In view of the enormous effort involved in such studies, this research should ideally involve collaboration across sites with specific expertise and prior basic agreement on methods that would allow for comparison and convergence across studies. Developing methodological frameworks that can be used whether the focus is on the consequences of terrorism or other traumatic situations 
would greatly enhance our understanding of the indicators of pathological responses to trauma. Ideally, researchers interested in investigating these issues would agree about methodological approaches and standardized instruments in advance of embarking on such studies post-trauma.

\section{Application of Risk Factors to the Prediction of PTSD on an Individual Level}

The development of almost any mental disorder is multidetermined involving several identified risk factors ranging from the genetic, prenatal, environmental, and behavioral. In medicine, clinicians match specific risk factors with patients in order to maximize preventive strategies and provide more focused intervention. For example, in cardiac disease, although familial risk, poor diet, lack of exercise, low HDL are all risk factors, a given patient may only have one of these risk factors (for example, low HDL), necessitating a different plan of care and treatment than a patient with other risk factors. Accordingly, genetic, familial, cognitive, behavioral, and personality risk factors for the development of psychopathology following exposure to trauma might also necessitate slightly different interventions or surveillance in the immediate aftermath of trauma. Although many risk factors have been identified as potentially involved in pathological responses to trauma, it is now time to determine which specific risk factors are most highly associated with the occurrence of PTSD, and which suggest specific treatment strategies.

\section{The Full Spectrum of Pathological Responses}

In any discussion of long-term pathologic responses following any traumatic event, there is an implicit assumption that the outcome being referred to is PTSD, or relatedcomorbid disorders. Yet PTSD is only one among several possible outcomes following trauma exposure. Trauma survivors are also at increased risk for the development of other mental disorders such as major depression, panic disorder, generalized anxiety disorder, and substance abuse, as well as persistent anxiety and distress that does not meet criteria for a specific psychological disorder compared to persons who have not experienced trauma (Kessler et al, 1995). Furthermore, they are at risk for developing more somatic symptoms and physical illnesses, particularly hypertension, asthma, chronic pain syndromes, and other psychosomatic illnesses (Boscarino, 1996). Since PTSD appears to represent only one type of response to trauma, that is neither inevitable nor prototypic, future studies must utilize a more broad based evaluation of trauma survivors both in the acute and chronic aftermath so as to ensure that we have captured the full spectrum of mental health consequences. Moreover, the relationship between mental and physical health will provide a more complete analysis of pathologic responses to terrorism.

\section{Interplay between Biological and Psychological Variables}

Although there is emerging information about the biological and psychologic variables that predict long-term pathology, there are no published studies that have examined the interplay of biological and psychological variables using a prospective, longitudinal design following terrorism. As stated above, the elucidation of biologic contributors to pathologic responses post-trauma will undoubtedly provide fruitful avenues for determining biologic strategies for prophylaxis or symptom reduction. There is a need for multivariate assessment of which set of distress measures, and possibly accompanying biologic and other risk factors that need to be considered in identifying people who will develop disorders. In recent years, most research has focused on a linear relationship between acute variables (eg panic, dissociation, appraisals) and subsequent disorder. A more accurate approach may involve multivariate consideration of these possible factors. For example, the contribution of acute dissociation or panic in the development of chronic disorder may be moderated by the relationship of these factors to pretrauma vulnerability factors, such as childhood abuse (Keane et al, 2001).

\section{Relationship between Shorter-Term Prospective Studies and Long-Term Studies of PTSD and Other Post-Trauma Outcomes}

Studies that have provided prospective, longitudinal data for several years following a traumatic event have been critical to our knowledge of how pathologic processes develop. Yet, a question remains about whether persons with PTSD 2 years following a terrorism event are comparable to subjects with PTSD decades later. Studies using a prospective, longitudinal approach have not been able to focus on 'delayed PTSD' or the issue of whether and how new life events can stimulate the development of PTSD symptoms for the first time. Planning such research requires a 10- or 20-year commitment of resources, usually not possible using traditional funding mechanisms.

\section{The Interplacy between Resilience vs Vulnerability}

The idea of resilience initially reflected that somehow, individuals could escape an inevitable fate if they had factors that increased their ability to withstand the normal psychological impact of an event. As researchers assert that the development of mental illness is a sign of pathology, and that most persons recover, it is difficult to know whether to define resilience in terms of the absence of pathology, or whether resilience might refer to a failure to develop almost any short- or long-term adverse consequences following trauma. It is also not clear whether resilience simply reflects the flipside of vulnerability. In any case, the importance of studying resilience is that it may be that the kind of traits and behaviors that do protect persons from long- or even short-terms symptoms can be learned. It is critical to incorporate biologic assessments to the study of resilience so as to develop models that would determine whether resilience is associated with different biologic mechanisms than those involved in recovery from stress.

\section{The Effects of Direct $v s$ Indirect Exposure to Terrorism}

As stated above, there is a need to differentiate between pathologic responses in those directly exposed, and among those who become anxious and impaired because they are 
frightened by eye witness news coverage, second-hand reports of what happened as told by survivors, or because of fears of subsequent attacks. It is critical to study vulnerability factors within the normal population that predict impairment following indirect exposure. Incorporating biologic assessments would substantially enhance an understanding of whether effects of those indirectly exposed are qualitatively similar to those that develop symptoms as a result of direct exposure.

\section{The Differential Effects of Terrorism in Groups at Special Risk for Exposure}

It is not clear whether persons who function in occupations as first responders to terrorism and trauma (police officers, firefighters, EMT workers) are at greater risk due to increased exposure, or lesser risk, due to constitutional protective factors and prior training and specific rolerelated duties, than do random citring the scale of terrorism, and its potential to impact on whole communities, there is a need to investigate the capacity to train individuals, or even communities, to minimize the effects of terrorism.

\section{Effect of Public Health Education and Media}

The roles of the mass media, the web, and other public education tools may be helpful in alleviating public distress. It may be that in those who are at risk for developing psychopathology, specific recommendations for minimizing exposure to media following terrorist attacks may be indicated. More than this, it may be possible to articulate guidelines for the types of communications that will be least likely to precipitate or augment symptomatology in the public. Without systematic study of these issues, it is unwarranted to make such recommendations.

\section{The Relationship Between Trauma Severity, Symptoms, and Treatment Seeking}

Although the city of New York prepared itself for a mental health epidemic in the early aftermath of $9 / 11$ by making mental heath intervention widely available and free of charge, far fewer persons presented for mental health treatment than were expected on the basis of predictions of the prevalence of PTSD and major depression in weeks and months following this event. It may be that the lack of treatment seeking behavior reflected the fact that $9 / 11$ was a low impact event in New York, or one that did not directly affect many people. However more likely, the statistics reflect a gap in our understanding of the conditions under which trauma survivors engage in help-seeking behavior, as well as the time at which they are mostly likely to do so. It is widely maintained by clinicians who treat trauma survivors that it can take several years, and sometimes decades, before trauma survivors with pathological responses in the aftermath of terrorism, initiate treatment. In guiding the public health responses to terrorism, it is critical to gain information about the characteristics of persons most likely to seek treatment in the early stages following trauma and several years later. It is not clearly understood whether persons who seek services immediately following exposure to a trauma, particularly a large-scale event, are different from those who are delayed help seekers. It is also critical to identify persons who develop PTSD-like syndromes even under conditions where the objective exposure factors to terrorism are of lower magnitude, or who develop a recrudescence of prior psychopathology due to the impact of terrorism. Prospective studies of the exposure and vulnerability factors of treatment seekers in the acute and chronic aftermath of terrorism will yield information that can be used for planning mental health needs in the aftermath of a disaster.

\section{DEFINITION OF PTSD: A BROADER QUESTION REQUIRING REEXAMINATION}

\section{Definition of PTSD: Time}

Attempting to delineate what makes a response pathological is difficult because it is not clear whether the presence of mental health symptoms following trauma exposure should be defined as a function of time, that is, using a 'recovery' model, or, alternatively, whether a pathological response following trauma exposure represents an alternative trajectory to the normative response. In the first model, trauma is defined by the persistence of symptoms that within a specified period of time immediately following the event would otherwise be considered normal (eg as opposed to 'pathological'). The second model posits that pathology is defined by the presence of a fundamentally different initial response to stress leading to a cascade of events that results in persistent symptoms of hyperarousal, recollection of intrusive events, and avoidance of reminders. In reevaluating the utility of the first model in the context of terrorism, and possibly other mass traumatic events, it may be prudent to define the timeline of recovery according to a wellspecified and realistic assessment of threat.

\section{Definition of PTSD: Symptoms}

The PTSD diagnosis was initially conceptualized in the absence of any prospective, longitudinal data about the natural course of symptoms, but rather, based on the clinical presentation of chronically symptomatic and often disabled patients. No attempt was made to differentiate the symptoms of trauma survivors, who appeared less disabled and showed greater overall functioning. It is now clear that trauma survivors who do not meet full diagnostic criteria for PTSD, and who appear to be functioning well (eg do not report high levels of subjective distress and largely maintain pre-exposure levels of occupational and relationship functioning) may still endorse experiencing intrusive symptoms such as distress at reminders of the traumatic event, and active avoidance symptoms such as forgetting aspects of the traumatic event and avoiding reminders of the event. Can these symptoms be considered pathological if they are not associated with subjective distress or impairment? Do more specific criteria reflecting the effect of trauma exposure on absenteeism from work, reduced productivity, loss of employment, and increased utilization of healthcare systems need to be included in assessing whether long-term responses are pathological? Without a re-examination of this issue, it becomes difficult to 
considering the trajectory from the acute response to pathology. Had PTSD been defined by the symptoms that remained after removing those also found in subjects found in subjects also exposed to trauma but without consequent functional impairment, we would now be in a better position to identify symptoms associated with a failure to recover and alternatively with resilience. The countervailing consideration, of course, is that common symptoms showing a dose-response relationship with exposure should be the hallmark symptoms of PTSD - a position consistent with the initial conceptual origin of PTSD as reflecting a universal response to an extremely unusual event (Yehuda and McFarlane, 1995). In the future, we should consider the possibility of decompacting our current notion of PTSD so that we generate outcome data with respect to reliving, avoidance, and hyperarousal symptoms, and functional outcome measures as individually rated dimensions so that we can determine which of these symptom dimensions are associated with dysfunction $v s$ aftereffects of exposure that will not substantially impair functioning.

\section{IS ENOUGH INFORMATION ABOUT PATHOLOGICAL RESPONSES AVAILABLE TO INFORM PUBLIC POLICY?}

Without a coordinated intellectual framework about the effects of psychological trauma, public policy makers cannot design effective public health responses to terrorism, and public education will result in the presentation of contradictory or incomplete information. The mental health response to the two main terrorist attacks in this country (the Oklahoma City bombing and the 9/11 attacks) was not guided by evidence-based medicine and psychology, but rather, but clinical lore and prior practices. As almost no systematic research was carried out about the nature of persons who needed or received services, it is not even clear to what extent the responses were successful or what should be done differently next time. As many opinion leaders raised the possibility that some interventions being used may have been contraindicated (McNally et al, 2003), it is clear that it is critical to obtain and to disseminate the proper information to mental health response teams on a large scale.

What we currently know justifies that, at a minimum, public health agencies should ensure that the natural recovery process is not impaired through any interventions provided in the initial stage. Although evidence is limited, it appears appropriate to provide educational information that supports activities that enhance safety, security, social support, that promotes the reduction of hyperarousal in the immediate phase. Often referred to as 'psychological first aid,' this approach does not presume that trauma survivors have a mental disorder, or in fact that a mental disorder needs to be prevented; instead, it assumes resilience in the majority of people and that meeting immediate their needs is the most appropriate step. Surveillance may be the key in the acute phase, so that people can be tracked and that when resources are needed they can be provided. This coupled with a general education approach about adaptive coping strategies that can be delivered as a public health rather than clinical intervention. Proper training might help to reduce the risk of pathological responses. The role of proper instructions in mass media tools needs to be studied.

\section{HOW CAN GAPS IN OUR KNOWLEDGE ABOUT THE EFFECTS OF TERRORISM BE FILLED?}

A significant barrier to collecting data in the aftermath of a terrorist attack involves the perception that victims of terrorism need to be 'protected' from research. Following the Oklahoma City bombing, the governor placed a moratorium on research, permitting only few investigators to study trauma survivors (North et al, 2002). This explains the relative paucity of data obtained, and most importantly, the lack of information specifically related to the effectiveness of the immediate mental health response funded through Federal Emergency Management Agency (FEMA), the Red Cross, or independent volunteers. Very shortly after 9/11 City and State officials discussed a plan for insuring the protection of potential subjects by creating a registry of survivors, and controlling who would be allowed to recruit them for studies. As in Oklahoma City, the sheer volume of outside resources, including personnel arriving from all over the world to 'respond' to 9/11, raised concerns that victims would be inundated with requests to participate in studies and would ultimately feel burdened by them.

Although it is appropriate to protect the welfare of potential research subjects, the subtext of any immediate bureaucratic response that seeks to place a moratorium on research is that even naturalistic research is something from which people need protection. The implication is that it is not altogether appropriate to conduct research in the immediate aftermath of a disaster. Such an attitude must be changed as a prerequisite to filling gaps in research.

The establishment of the Department of Homeland Security implies a preparedness to prevent and respond to terrorism that should be extended to mental health research. A by-product of the response to terrorism is that the public is now duly informed about the reasons it must submit to searches at airports or show ID cards when entering any public building. Similarly, the public needs to be alerted to the necessity of research and prepared for the operational research procedures that would be implemented in the aftermath of terrorist attack. In preparation for this, spokespersons from the academic community must develop forums now through which they can communicate to the public the rationale for specific scientific questions and the greater good expected by the production of scientific/ medical knowledge. It is imperative to develop a culture of education in which the academic community can freely communicate what is and is not known, such that survivors of terrorism will understand the value of their participation in research to the generation of useful knowledge.

Concurrently, plans should be made for the type of research that should be instituted following a national terrorist attack. The time to discuss critical variables, articulate the appropriate outcome measures, design databases and templates for assessment, devise strategies for treatment-matching or simply different levels of interventions based on specific psychological reactions of the survivor, and in consideration of the differential levels of training and education of those responding on the scene 
is before the next terrorist attack. Manuals, websites, and training could be prepared that deliver the important message that as with emergency measures in medicine, the delivery of psychological services also requires a 'triage' process. Funding should be set aside for such projects, and persons identified and trained in advance who would implement the project.

At least some of the necessary research could be implemented as part of the national governmental response. This is potentially feasible to the extent that there would already exist an established relationship between those responding to a disaster and those who will be asked to study the response. This, in turn, requires that the acquisition of knowledge become a priority for the government and those involved in the immediate delivery of services, not only for the academic community.

The issues involved in establishing such an infrastructure are complex. A major hurdle is the protection of the right to privacy of survivors. The inability to study the disasters that have recently occurred is in some way due to the paucity of paperwork generated by those providing services, which may be intentional. Indeed, the ability to receive services anonymously was a major component of both the Oklahoma City and New York response, and was done in order to reduce as many barriers (eg stigma) as possible to accessing care.

The assumption that survivors would be hesitant to obtain services unless they can do so anonymously should be verified. Possibly as the public becomes more concerned for their safely and welfare, they would be willing to tolerate the costs associated with being better prepared to respond to disaster, as they are also willing to tolerate increased security at airports or some restrictions on the right to privacy. It is likely to be the case that no infrastructure for research can be implemented in the absence of public education or representation in such future plans. The inclusion of medical ethicists would also allow a consideration of how consent to use information for research can be obtained by those delivering services during times of crises, or even, proactively as in the case of organ donations on driver's licenses, etc. Similar challenges have been addressed in emergency medicine, for example in the development of guidelines for the ethical conduct of randomized clinical trials of novel medications for immediate treatment of individuals presenting with heart attacks or strokes.

\section{REFERENCES}

Andrews B, Brewin CR, Rose S, Kirk M (2000). Predicting PTSD in victims of violent crime: the role of shame, anger and blame. $J$ Abnormal Psychol 109: 69-73.

American Psychiatric Association (1994). Diagnostic and Statistical Manuel-IV-R. American Psychiatric Press: Washington.

Bohus B, Lissak K (1968). Adrenocortical hormones and avoidance behaviour of rats. Int J Neuropharmacol 7: 301-306.

Boscarino JA (1996). Posttraumatic stress disorder, exposure to combat, and lower plasma cortisol among Vietnam veterans: findings and clinical implications. J Consul Clin Psychol 64: 191-201.

Breslau N, Chilcoat HD, Kessler RC, Davis G (1999). Previous exposure to trauma and PTSD effects of subsequent trauma: results from the Detroit Area Survey of Trauma. Am J Psychiatry 156: 902-907.
Breslau N, Davis GC, Andreski P, Peterson E (1991). Traumatic events and posttraumatic stress disorder in an urban population of young adults. Arch Gen Psychiatry 48: 216-222.

Brewin CR, Andrews B, Rose S, Kirk M (1999). Acute stress disorder and posttraumatic stress disorder in victims of violent crime. Am J Psychiatry 156: 360-366.

Brewin CR, Andrews B, Valentine JD (2000). Meta-analysis of risk factors for posttraumatic stress disorder in trauma-exposed adults. J Consult Clin Psychol 68: 748-766.

Brunet A, Weiss DS, Metzler TS, Best SR, Neylan TC, Rogers C et al (2001). The peritraumatic distress inventory: a proposed measure of PTSD criterion A2. Am J Psychiatry 158: 1480-1485.

Bryant RA (2003). Early predictors of posttraumatic stress disorder. Biol Psychiatry 53: 789-795.

Bryant RA, Harvey AG (1998). Relationship of acute stress disorder and posttraumatic stress disorder following mild traumatic brain injury. Am J Psychiatry 155: 625-629.

Bryant RA, Harvey AG (2002). Delayed-onset posttraumatic stress disorder: a prospective study. Aust NZ J Psychiatry 36: 205-209.

Bryant RA, Harvey AG, Guthrie R, Moulds M (2000). A prospective study of acute psychophysiological arousal, acute stress disorder, and posttraumatic stress disorder. J Abnormal Psychol 109: 341-344.

Bryant RA, Panasetis P (2001). Panic symptoms during trauma and acute stress disorder. Behav Res Ther 39: 961-966.

Buckley TC, Blanchard EB, Hickling EJ (1996). A prospective examination of delayed onset PTSD secondary to motor vehicle accidents. J Abnormal Psychol 105: 617-625.

Bush G, Luu P, Posner MI (2000). Cognitive and emotional influences in anterior cingulate cortex. Trends Cogn Sci 4: 215-222.

Cahill L, Prins B, Weber M, McGaugh JL (1994). Adrenergic activation and memory for emotional events. Nature 371: 702-704.

Charney DS, Deutch AY, Krystal JH, Southwick SM, Davis M (1993). Psychobiologic mechanisms of posttraumatic stress disorder. Arch Gen Psychiatry 50: 295-305.

Dancu CV, Riggs DS, Hearst-Ikeda D, Shoyer BG, Foa EB (1996). Dissociative experiences and posttraumatic stress disorder among female victims of criminal assault and rape. J Traum Stress 9: 253-267.

Delahanty DL, Herberman HB, Craig KJ, Hayward MC, Fullerton CS, Ursano RJ et al (1997). Acute and chronic distress and posttraumatic stress disorder as a function of responsibility for serious motor vehicle accidents. J Consult Clin Psychol 65: 560-567.

Delahanty DL, Riamonde AJ, Spoonster E (2000). Initial posttraumatic urinary cortisol levels predict subsequent PTSD symptoms in motor vehicle accident victims. Biol Psychiatry 48: 940-947.

de Quervain DJ, Roozendaal B, Nitsch RM, McGaugh JL, Hock C (2000). Acute cortisone administration impairs retrieval of longterm declarative memory in humans. Nat Neurosci 3: 313-314.

Difede J, Ptacek JT, Roberts JG, Barocas D, Rivers W, Apfeldorf WJ et al (2002). Acute stress disorder after burn injury: a predictor of posttraumatic stress disorder. Psychosomatic Med 64: 826-834.

Dunmore E, Clark DM, Ehlers A (2001). A prospective investigation of the role of cognitive factors in persistent PTSD after physical and sexual assault. Behav Res Ther 39: 1063-1084.

Ehlers A, Mayou RA, Bryant B (1998). Psychological predictors of chronic PTSD after motor vehicle accidents. J Abnormal Psychol 107: 508-519.

Galea S, Ahern J, Resnick H, Kilpratric D, Bucuvalas M, Gold J et al (2002). Psychological sequelae of the September 11 terrorist attacks. New Engl J Med 346: 982-987.

Galea S, Boscarino J, Resnik H, Vlahov D (2003). Trends of probable post-traumatic stress disorder in New York City after the September 11 terrorist attacks. Am J Epidemiol 158: 514-524. 
Gilbertson MW, Shenton ME, Ciszewski A, Kasai K, Lasko NB, Orr SP et al (2002). Smaller hippocampal volume predicts pathologic vulnerability to psychological trauma. Nat Neurosci 5: 1242-1247.

Green BL, Lindy JD, Grace MC, Gleser GC, Leonard AC, Korol M et al (1990). Buffalo Creek survivors in the second decade: stability of stress symptoms. Am J Orthopsychiatry 60: 43-54.

Guthrie RM, Bryant RA (2005). Auditory startle response in firefighters before and after trauma exposure. Am J Psychiatry 162: 283-290.

Harvey AG, Bryant RA (1998). Relationship of acute stress disorder and posttraumatic stress disorder following motor vehicle accidents. J Consult Clinl Psychol 66: 507-512.

Harvey AG, Bryant RA (1999). A two-year prospective evaluation of the relationship between acute stress disorder and posttraumatic stress disorder. J Consult Clin Psychol 67: 985-988.

Harvey AG, Bryant RA (2000). A two-year prospective evaluation of the relationship between acute stress disorder and posttraumatic stress disorder following mild traumatic brain injury. $\mathrm{Am} \mathrm{J}$ Psychiatry 157: 626-628.

Harvey AG, Bryant RA (2002). Acute stress disorder: a synthesis and critique. Psychological Bull 128: 892-906.

Holeva V, Tarrier N, Wells A (2001). Prevalence and predictors of acute stress disorder and PTSD following road traffic accidents: thought control strategies and social support. Behav Ther 32: 65-83.

Holsboer F (2001). The corticosteroid receptor hypothesis of depression. Neuropsychopharmacol 23: 477-501.

Keane TM, Kaufman ML, Kimble MO (2001). Peritraumatic dissociative symptoms, acute stress disorder, and the development of posttraumatic stress disorder: Causation, correlation or epiphenomena. In: Sanchez-Planell L, Diez-Quevedo C (eds). Dissociative States. Springer-Verlag: Barcelona. pp 21-43.

Kessler RC, Sonnega A, Bromet E, Hughes M, Nelson CB (1995). Posttraumatic stress disorder in the National Comorbidity Survey. Arch Gen Psychiatry 52: 1048-1060.

Klimesch W, Doppelmayr M, Russegger H, Pachinger T (1996). Theta band power in the human scalp EEG and the encoding of new information. Neuroreport 7: 1235-1240.

Koopman C, Classen C, Cardena E, Spiegel D (1995). When disaster strikes, acute stress disorder may follow. J Traum Stress 8: 29-46.

Koopman C, Classen C, Spiegel D (1994). Predictors of posttraumatic stress symptoms among survivors of the Oakland/ Berkeley, Calif., firestorm. Am J Psychiatry 151: 888-894.

Maes M, Delmeire L, Mylle J, Altamura C (2001). Risk and preventive factors of post-traumatic stress disorder (PTSD): alcohol consumption and intoxication prior to a traumatic event diminishes the relative risk to develop PTSD in response to that trauma. J Affect Disord 63: 113-121.

Marmar C, Best S, Metzler T, Chemtob C, Gloria R, Killeen A et al (2003). Impact of the World Trade Center attacks on New York City Police Officers; a prospective study, unpublished data.

Marmar C, Weiss D, Metzler T, Delucchi K, Best S (1999). Longitudinal course and predictors of continuing distress in emergency services personnel. J Nerv Ment Dis 187: 15-22.

Marmar C, Weiss D, Schlenger W, Fairbank J, Jordan B, Kulka R et al (1994). Peritraumatic dissociation and post-traumatic stress in male Vietnam theater veterans. Am J Psychiatry 151: 902-907.

Marshall GN, Schell TL (2002). Reappraising the link between peritraumatic dissociation and PTSD symptom severity: evidence from a longitudinal study of community violence survivors. J Abnormal Psychol 111: 626-636.

Mayou R, Bryant B, Duthrie R (1993). Psychiatric consequences of road traffic accidents. Br Med J 307: 647-651.

McFarlane AC (1989). The aetiology of post-traumatic morbidigy: predisposing, precipitating and perpetuating factors. $\mathrm{Br} J$ Psychiatry 154: 221-228.
McNally RJ (2003). Psychological mechanisms in acute response to trauma. Biol Psychiatry 53: 779-788 (Review).

Murray J, Ehlers A, Mayou RA (2002). Dissociation and posttraumatic stress disorder: two prospective studies of road traffic accident survivors. Br J Psychiatry 180: 363-368.

Neylan TC, Lenoci M, Maglione ML, Rosenlicht NZ, Metzler TJ, Otte C et al (2003). Delta sleep response to metyrapone in post-traumatic stress disorder. Neuropsychopharmacology 28: $1666-1676$.

Nishith P, Mechanic MB, Resick PA (2000). Prior interpersonal trauma: the contribution to current PTSD symptoms in female rape victims. J Abnormal Psychol 109: 20-25.

North CS, Pfefferbaum B, Tucker P (2002). Ethical and methodological issues in academic mental health research in populations affected by disasters: the Oklahoma City experience relevant to September 11, 2001. CNS Spectr 7: 580-584.

Orr S (1997). Psychophysiologic reactivity to trauma-related imagery in PTSD: diagnostic and theoretical implications of recent findings. In: Yehuda R, McFarlane AC (eds). Psychobiology of Posttraumatic Stress Disorder, Vol. 821. New York Academy of Sciences: New York, NY. pp 114-124.

Orr SP, Metzger LJ, Lasko NB, Macklin ML, Hu FB, Shalev AY et al (2003). Physiologic responses to sudden, loud tones in monozygotic twins discordant for combat exposure: association with posttraumatic stress disorder. Arch General Psychiatry 60: 283-288.

Ozer EJ, Best SR, Lipsey TL, Weiss DS (2003). Predictors of posttraumatic stress disorder and symptoms in adults: a metaanalysis. Psychol Bull 129: 52-73.

Pacak K, Palkovitz M, Kopin IJ, Goldstein DS (1995). Stress-induced norepinephrine release in the hypothalamic paraventricular nucleus and pituitary-adrenocortical and sympathoadrenal activity: in vivo microdialysis studies. Front Neuroendocrinol 16: 89-150.

Pitman RK, Sanders KM, Zusman RM, Healy AR, Cheema F, Lasko NB et al (2002). Pilot study of secondary prevention of posttraumatic stress disorder with propranolol. Biol Psychiatry 15: $189-192$.

Pitman RK, Shalev AY, Orr SP (2000). Posttraumatic stress disorder: emotion, conditioning, and memory. In: MD Corbetta, MS Gazzaniga (eds). The New Cognitive Neurosciences. Plenum Press: New York. pp 687-700.

Post RM, Weiss SR, Smith MA (1995). Sensitization and kindling: Implications for the evolving neural substrates of post-traumatic stress disorder, in neurobiological and clinical consequences of stress: from normal adaptation to post-traumatic stress disorder. In: Friedman MJ, Charney DS, Deutch AY (eds). LippincottRaven Publishers: Philadelphia. pp 203-224.

Rausch LS, Shin LM, Pitman RK (1997). Evaluating the effects of psychological trauma using neuroimaging techniques. In: Yehuda R (ed). Psychological Trauma. Annual Review of Psychiatry, Vol. 17. APA Press: Washington, DC. pp 67-96.

Resnick HS, Yehuda R, Foy DW, Pitman R (1995). Effect of prior trauma on acute hormonal response to rape. Am J Psychiatry 15: 1675-1677.

Schnyder U, Moergeli H, Klaghofer R, Buddeberg C (2001). Incidence and prediction of posttraumatic stress disorder symptoms in severely injured accident victims. Am J Psychiatry 158: $594-599$.

Schuster MA, Stein BD, Jaycox L, Collins RL, Marshall GN, Elliott MN et al (2001). A national survey of stress reactions after the September 11, 2001, terrorist attacks. N Engl J Med 345: 1507-1512.

Shalev AY (1992). Posttraumatic stress disorder among injured survivors of a terrorist attack: predictive value of early intrusions and avoidane symptoms. J Nerv Ment Dis 180: 505-509.

Shalev AY, Freedman S, Peri T, Brandes D, Sahar T, Orr SP et al (1997). Predicting PTSD in trauma survivors: prospective 
evaluation of self-report and clinician-adminisntered instruments. Br J Psychiatry 170: 558-564.

Shalev AY, Freedman S, Peri T, Brandes D, Sahar T, Orr SP et al (1998a). Prospective study of posttraumatic stress disorder and depression following trauma. Am J Psychiatry 155: 630-637.

Shalev AY, Peri T, Brandes D, Freedman S, Orr SP, Pitman RK (2000). Auditory startle response in trauma survivors with posttraumatic stress disorder: a prospective study. $A m \mathrm{~J}$ Psychiatry 157: 255-261.

Shalev AY, Sahar T, Freedman S, Peri T, Glick N, Brandes D et al (1998b). A prospective study of heart rate response following trauma and the subsequent development of posttraumatic stress disorder. Arch Gen Psychiatry 55: 553-559.

Shin LM, Whalen PJ, Pitman RK, Bush G, Macklin ML, Lasko NB et al (2001). An fMRI study of anterior cingulate function in posttraumatic stress disorder. Biol Psychiatry 50: 932-942.

Simeon D, Guralnik O, Knutelska M, Yehuda R, Schmeidler J (2003). Basal norepinephrine in depersonalization disorder. Psychiatry Res 121: 93-97.

Silva RR, Alpert M, Munoz DM, Singh S, Matzner F, Dummitt S (2000). Stress and vulnerability to posttraumatic stress disorder in children and adolescents. Am J Psychiatry 157: 1229-1235.

Smith K, Bryant RA (2000). The generality of cognitive bias in acute stress disorder. Behav Res Ther 38: 709-715.

Solomon Z, Kotler M, Shalev A, Lin R (1989). Delayed onset PTSD among Israeli veterans of the 1982 Lebanon war. Psychiatry 52: 428-436.

Southwick SM, Krystal JH, Bremner JD, Morgan III CA, Nicolaou AL, Nagy LM et al (1997). Noradrenergic and serotonergic function in posttraumatic stress disorder. Arch Gen Psychiatry 54: 749-758.

Southwick SM, Krystal JH, Morgan CA, Johnson D, Nagy LM, Nicolaou A et al (1993). Abnormal noradrenergic function in posttraumatic stress disorder. Arch Gen Psychiatry 50: 266-274.

Staab JP, Grieger TA, Fullerton CS, Ursano RJ (1996). Acute stress disorder, subsequent posttraumatic stress disorder and depression after a series of typhoons. Anxiety 2: 219-225.

Stein MB, Jang KL, Taylor S, Vernon PA, Livesley WJ (2002). Genetic and environmental influences on trauma exposure and posttraumatic stress disorder symptoms: a twin study. $A m J$ Psychiatry 159: 1675-1681.

True WR, Rice J, Eisen SA, Heath AC, Goldberg J, Lyons MJ et al (1993). A twin study of genetic and environmental contributions to liability for posttraumatic stress disorder. Arch Gen Psychiatry 50: $257-264$

Vaiva G, Thomas P, Ducrocq F, Fontaine M, Boss V, Devos P et al (2004). Low posttrauma GABA plasma levels as a predictive factor in the development of acute posttraumatic stress disorder. Biol Psychiatry 55: 250-254.

Wakefield JC (1996). DSM-IV: are we making diagnostic progress? Contemp Psychol 41: 646-652.

Wong CM (2002). Post-traumatic stress disorder: advances in psychoneuroimmunology. Psychiatr Clin N Am 25: 369-383, vii (Review).

Yehuda R (1999a). Biological factors associated with susceptibility to posttraumatic stress disorder. Can J Psychiatry 44: 34-39.

Yehuda R (1999b). Risk Factors for Postraumatic Stress Disorder. American Psychiatric Press: Washington, DC.

Yehuda R (2002). Posttraumatic stress disorder. New Engl J Med 346: 108-114.

Yehuda R, Bierer LM, Schmeidler J, Aferiat DH, Breslau I, Dolan S (2000). Low cortisol and risk for PTSD in adult offspring of holocaust survivors. Am J Psychiatry 157: 1252-1259.

Yehuda R, Halligan SL, Bierer LM (2001). Relationship of parental trauma exposure and PTSD to PTSD, depressive and anxiety disorders in offspring. J Psychiatric Res 35: 261-269.

Yehuda R, McFarlane AC (1995). Conflict between current knowledge about posttraumatic stress disorder and its original conceptual basis. Am J Psychiatry 152: 1705-1713.

Yehuda R, McFarlane AC, Shalev AY (1998). Predicting the development of posttraumatic stress disorder from the acute response to a traumatic event. Biol Psychiatry 44: 1305-1313 (Review).

Zangrossi Jr H, Viana MB, Graeff FG (1999). Anxiolytic effect of intra-amygdala injection of midazolam an 8-hydroxy-2-(di-npropylamino) tetralin in the elevated T-maze. Eur J Pharmacol 369: $267-270$ 